\title{
Research on the Demand for Barrier Free Products Based on Different Degrees of Disability
}

\author{
Di Yu \\ North China Electric Power University, Baoding 071000, China \\ 976785983@qq.com
}

Keywords: barrier free design, One-Armed, home furnishing, kitchen island.

\begin{abstract}
In order to let the body missing can be anywhere convenient, "accessibility" has become more and more factors that designers consider. What is "accessibility", how to design a qualified "barrier free products" is the main research topic, and the armed people of barrier free design through the design of Home Furnishing survey etc. that is, the "barrier free kitchen operation platform.
\end{abstract}

\section{Introduction}

Due to various irresistible factors due to the different degree of limb deficiencies, such as earthquake, fire, accident, innate, greatly influences people's daily life. It not only makes people's physiological pain, in the days after the life in the event of any inconvenience caused the moment, will make the psychological trauma caused two times as much as possible. In order to compensate for the physical and psychological trauma, we provide the basis of the prosthesis, should optimize the environment for the basic Home Furnishing and outdoor environment. The barrier free design is to meet this demand.

\section{Barrier free design}

\subsection{What does "barrier free design" mean?}

The concept of "barrier free design". Beginning in 1974, the new design is put forward by the United Nations Organization. The barrier free design in modern society emphasizes the development of science and technology, everything about human basic necessities of life of public space environment and various building facilities, planning and design of equipment, must fully consider the recession with a different degree of physical disability defect and the normal activities, such as the disabled, elderly people's needs, equipped with can response, meet those needs service function and device, build a loving and caring, protect human safety, convenient, comfortable modern living environment.

The first barrier free design in urban construction, transportation, public facilities and the environment to reflect the indicator system, such as pedestrian lanes for the blind laying aisle, tactile indication map, for people in wheelchairs dedicated bathrooms, public telephone, audio-visual guide to both double operation of bank auto teller machine, and then extended life to work, all kinds of entertainment appliances use. More than twenty years, starting from the design idea of caring human being vulnerable people's point of view, with the ideal goal of higher level to promote the development and progress of the design, make people create products more reasonable, kind and humane.

For example, looks very ordinary container, which has a clever "shared" design: a set of matching use of shampoo and hair conditioner, two identical containers, only in one adds a convex tactile perception mark cable, can cause the human touch is shampoo or conditioner. This small design, not only eliminates the blind use of barriers for general users, but also a very grateful for the kind of shampoo design does not have eyes can distinguish. Similar design and stereo headset, to distinguish the convex and concave beads around, is not only the appearance of exquisite decoration that is real "Sharing" is designed to "touch perceptual information". 
Thus, the use of the product interface design for perception mode selection is decided to implement the "share" the key of the product can. Because human perception has many "channels", such as visual, auditory, tactile, and the lack of just one channel only. Therefore, "multi channel" perception of products with superior performance barrier use.

No ideal barrier design is "accessibility". Based on the detailed research on human behavior, consciousness and action, is committed to optimizing design for all objects and environment by the people, in the use of the user interface allows users to remove those confused, difficult "disorder", provide the greatest possible convenience for this is the basic idea of the user, no barrier design.

\subsection{The difference between barrier free design and general design}

Barrier free design and universal design are similar, because the general design is designed for all people are common, but the key for barrier free design from the disabled and the elderly. But with the development of barrier free design, more and more people are aware of its limitations, so today's barrier free design is general the design of the close. And because the barrier free design in Chinese appeared relatively late, so most people will be equal to general design barrier free design.

\section{Design research}

\subsection{Target group survey}

In 2006, China conducted second sampling survey of disabled population, the number of disabled accounted for $6.39 \%$ of the number of sampling, the number of the total number of disabled disabled sampling 29.75\%. Age disability number as shown below.

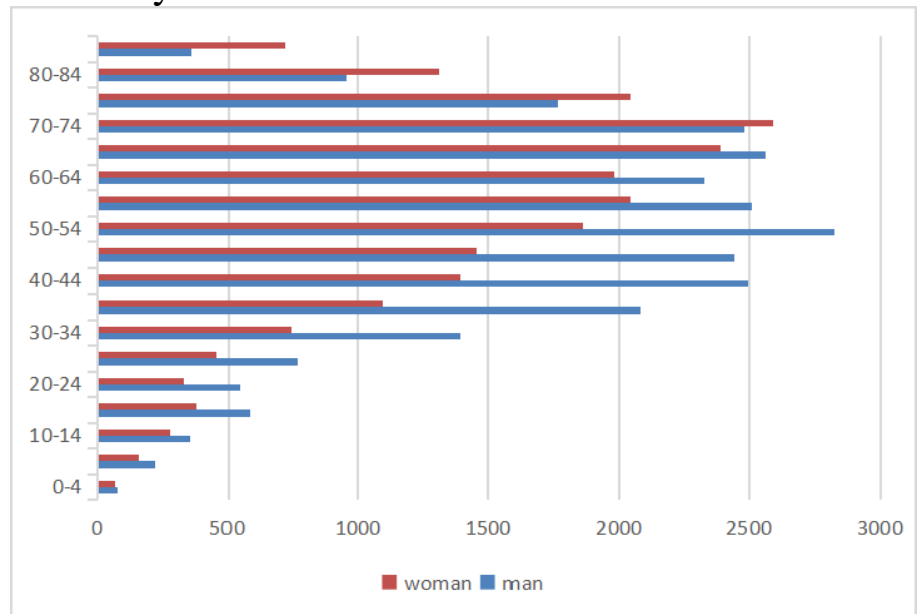

Fig. 12006 second disability census - limb disability Table 1 Three Scheme comparing

\begin{tabular}{|c|c|c|c|c|c|}
\hline & $\begin{array}{c}\text { extremity } \\
\text { disability }\end{array}$ & disability population & total sample size & $\begin{array}{c}\text { percentage } \\
1\end{array}$ & $\begin{array}{c}\text { percentage } \\
2\end{array}$ \\
\hline man & 26737 & 83342 & 1280011 & $32.08 \%$ & $6.51 \%$ \\
\hline woman & 21308 & 78137 & 1246134 & $27.27 \%$ & $6.27 \%$ \\
\hline sum & 48045 & 161479 & 2526145 & $29.75 \%$ & $6.39 \%$ \\
\hline
\end{tabular}

Prosthetics and orthotics to repair the defect of the way can really let people get treatment. The disability distribution of all ages can be seen that the disabled are mostly clustered in between 35 to 75 years old. The economic capacity is low or older people, facilitate their use of the product than the prosthesis or appliance is more suitable. 


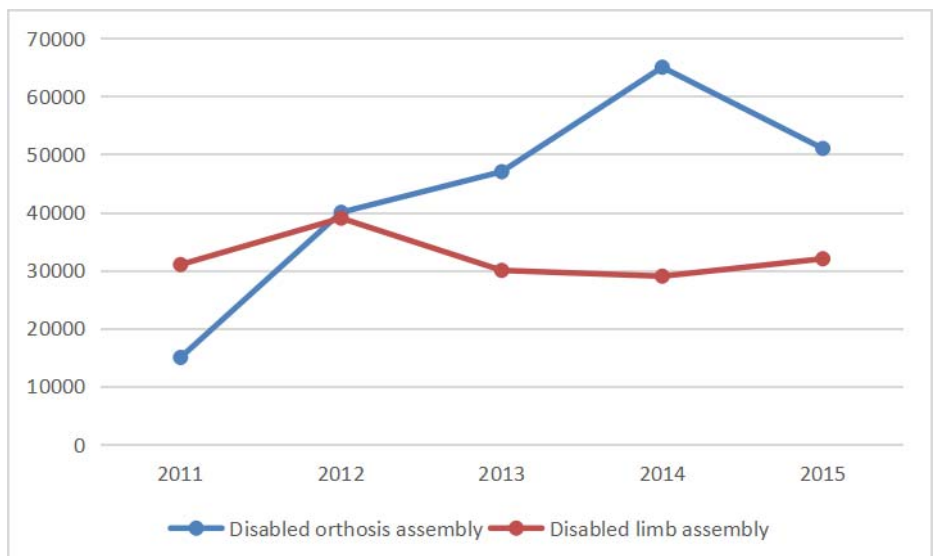

Fig. 2 Assembly of prostheses and orthoses from 2011 to 2015

Seen from the statistical graph, the number of the prosthetic gradually flat trend, even in the 2013 to 2014 decreased slightly; the number of installed appliances is the rapid growth in 2011 to 2014, but from 2014 to 2015, the number fell sharply.

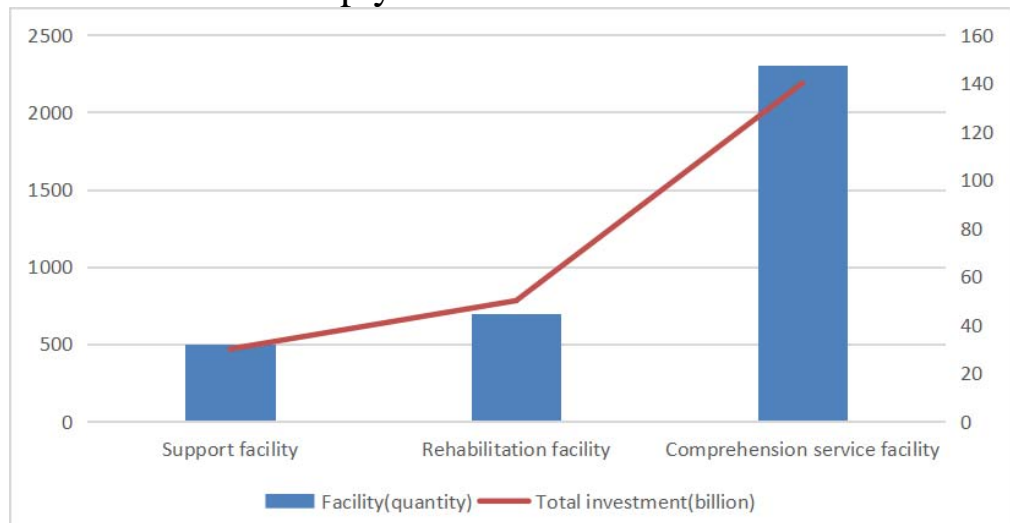

Fig. 3 Construction of service facilities for disabled persons in 2015

Can be seen from Figure 3, the state has invested a lot of money and experience in service facilities, especially the comprehensive service facilities. The purpose is to let the disabled people do not feel constrained and not convenient in daily life, even if the outside can also be disabled people everywhere convenient service facilities and channels. Based on this point. The designer has the obligation to facilitate their use for the disabled in product design.

\subsection{Target group}

Many of the tools in the design when considering only a convenient right grip, and left-handed users in life and not the minority. Especially the daily frequently used tools, the use of reverse will not only feel uncomfortable, will make people feel so upset. One for a product to say, right hand can be used particularly important. This barrier free design of the target group is armed groups, which requires the design of products to the right hand can be used conveniently. In summary, I designed this product of the target group is handicapped.

\section{Barrier free kitchen table}

\subsection{Design thought}

Firstly, on the whole hierarchical layout, saves the use of space, improve the utilization rate of unit area; secondly the function will be stirring, rub, cutting and other functions in a body, the system includes each step for cooking, improve efficiency; thirdly, the product itself can also withstand the belly, complete open, slicing action; finally, in the material, the product can all grip part has uniform color, easy to clean and non slip material. 


\subsection{Product display}
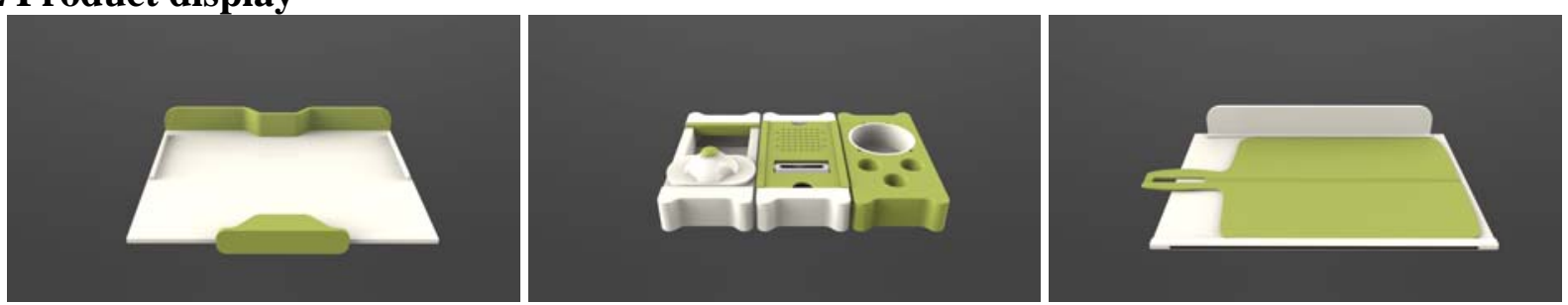

Fig. 4 Barrier free kitchen table

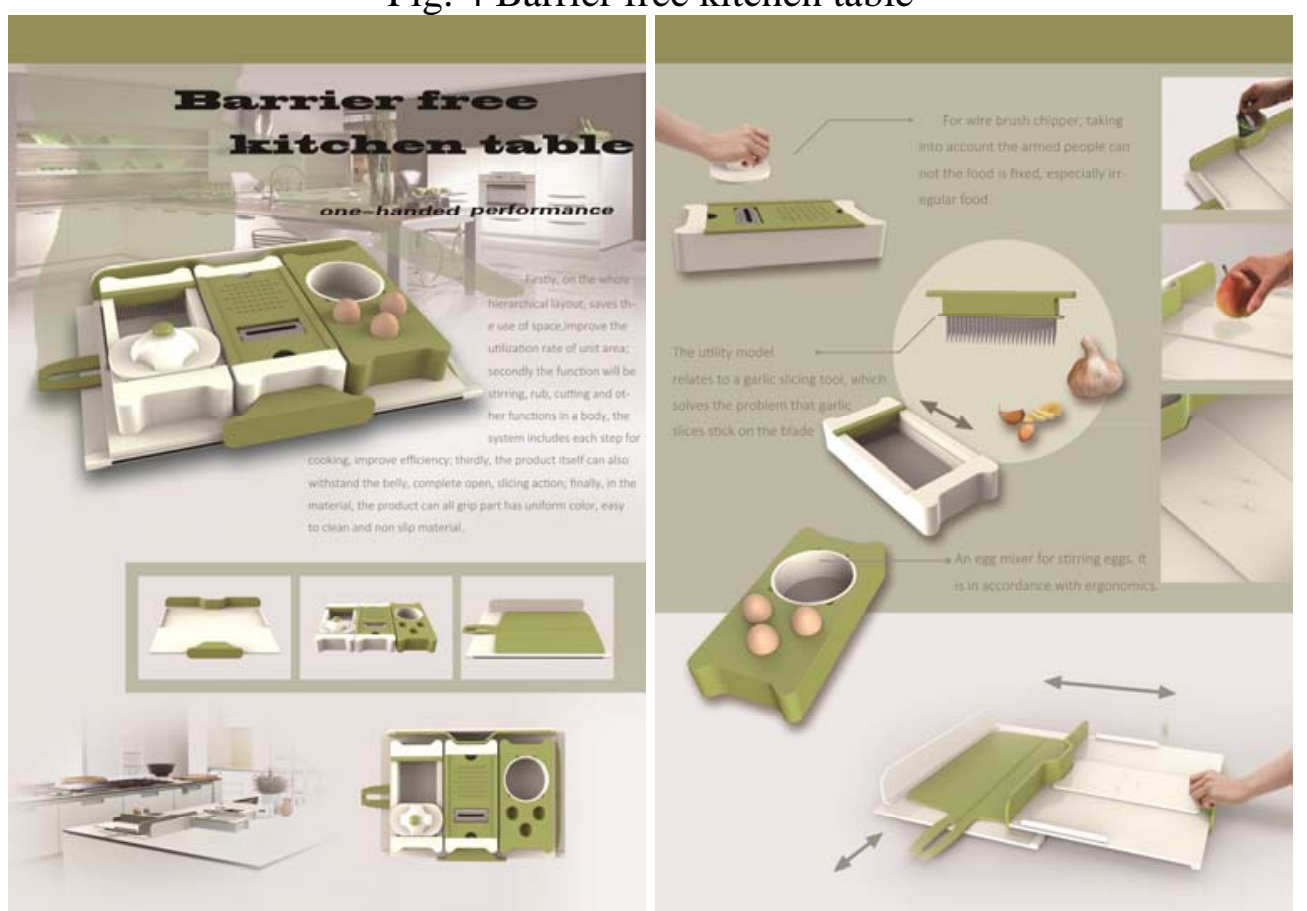

Fig. 5 Product show bill

\section{Conclusion}

In modern society, the rapid development of science and technology, everything about human basic necessities of life of public space environment and interior design Home Furnishing, must fully consider the recession with a different degree of physical disability defective and normal activities, equipped with can response and meet the needs of the service function and device, build a loving and caring, and human security, convenient, comfortable modern living environment.

\section{References}

[1] Information on http://sousuo.gov.cn/column/17852/0.htm

[2] Information on https://wenku.baidu.com/view/508dfec04028915f804dc2bf.html

[3] Information on http://baike.baidu.com 